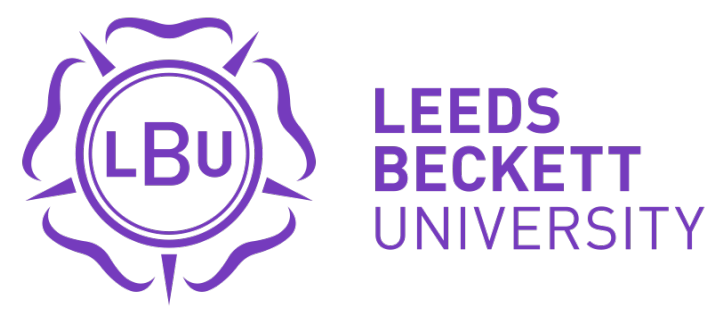

Citation:

Hulton, AT and Flower, D and Murphy, R and Richardson, D and Drust, B and Curran, K (2016) Effectiveness of a community football programme on improving physiological markers of health in a hard-to-reach male population: the role of exercise intensity. Soccer and Society, 17 (2). 196 - 208. ISSN 1466-0970 DOI: https://doi.org/10.1080/14660970.2015.1082750

Link to Leeds Beckett Repository record:

https://eprints.leedsbeckett.ac.uk/id/eprint/2002/

Document Version:

Article (Accepted Version)

The aim of the Leeds Beckett Repository is to provide open access to our research, as required by funder policies and permitted by publishers and copyright law.

The Leeds Beckett repository holds a wide range of publications, each of which has been checked for copyright and the relevant embargo period has been applied by the Research Services team.

We operate on a standard take-down policy. If you are the author or publisher of an output and you would like it removed from the repository, please contact us and we will investigate on a case-by-case basis.

Each thesis in the repository has been cleared where necessary by the author for third party copyright. If you would like a thesis to be removed from the repository or believe there is an issue with copyright, please contact us on openaccess@leedsbeckett.ac.uk and we will investigate on a case-by-case basis. 


\title{
Effectiveness of a Community Football Programme on Improving Physiological Markers of Health in a Hard-To-Reach Male Population: The Role of Exercise Intensity.
}

Andrew Thomas Hulton ${ }^{* a}$, David Flower ${ }^{\mathrm{b}}$, Rebecca Murphy ${ }^{\mathrm{a}}$, Dave Richardson ${ }^{\mathrm{a}}$, Barry Drust ${ }^{\mathrm{a}}$, Kathryn Curran ${ }^{\mathrm{c}}$.

a The Football Exchange, Research Institute for Sport and Exercise Sciences, Liverpool John Moores University, Liverpool, UK b Everton Football Club, UK

cCentre for Active Lifestyles, Institute for Sport, Physical Activity and Leisure, Carnegie Faculty, Leeds Beckett University, Leeds, UK.

\begin{abstract}
The present study evaluated the effectiveness of participation in recreational football during a community health programme, on physiological markers of health within a hard to reach (HTR) population. Nine men (Age: $33 \pm 9$ years, Mass: $75.4 \pm 13.7 \mathrm{~kg}$, Height: $1.74 \pm 0.07 \mathrm{~m}$ and Body Fat: $19 \pm 2 \%$ ) were recruited to participate in the study in collaboration with an English Premier League Football Club. Participants completed the 12-week football-based programme which included two coached football sessions each week. Physiological tests for blood pressure, resting heart rate,cholesterol and an anthropometrical test for body composition were completed at 3 time points during the study (Weeks-1, 6 and 12) in an attempt to evaluate the impact of the intervention on health. During each training session, measurements of intensity $\left(\% \mathrm{HR}_{\max }\right.$, identified from the yoyo intermittent level 1 test), duration and rating of perceived exertion were made. The 12-week programme (mean $\mathrm{HR}_{\max }$ throughout programme $=75 \pm 4 \%$ beats. min $^{-}$ 1; mean RPE throughout programme $=6 \pm 1$ ) elicited few changes in physiological markers of health with the only significant change been a decrease in resting heart rate from weeks $6-12$ $\left(87 \pm 22\right.$ beats. $\min ^{-1}$ at week- 6 , to $72 \pm 17$ beats. $\left.\min ^{-1} ; \mathrm{p}<0.05\right)$. This data would suggest that the current community football-related health projectwas not effective in improving physiological markers of health, but was able to maintain their level of health. A lack of improvementmay be
\end{abstract}

*Corresponding author. Email: a.t.hulton@lijmu.ac.uk 
due to the low intensity of sessions and a lack of coach education for the promotion of sessions that aim to improve health.

\section{Introduction}

The uptake of traditional health services (General Practices) by men is a cause for concern amongst public health professionals in the $\mathrm{UK}^{1}$. Individuals from hard-to-reach (HTR) populations experience difficulty engaging in physical activity for a sustained period of time ${ }^{2}$. Hard-to-reach populations are those who are difficult to access due to a specific factor that characterises its members (homeless people, prostitutes, drug addicts), which results in marginalization and restricted access to appropriate health care due to social barriers created by ignorance, prejudice and discrimination ${ }^{3}$ from the general population. Targeting health intervention is therefore an important factor in engaging HTR male populations who may be predisposed to cardiovascular health concerns ${ }^{4}$.

Interventions that use popular sports such as football as the exercise stimulus have been developed as a way to engage with HTR populations. Football may have a great potential to act as a health promotion tool as a consequence of its ability to improve the motivational and social factors associated with its participation when compared to more traditional types of exercise interventions such as continuous moderate intensity running 5 . In order to remove the barriers for male participation it has been suggested ${ }^{6}$ that sports groups may serve as the most appropriate community setting for these populations, as traditional health care advice is typically dominated by female friendly practises which make male populations regard themselves as intruders ${ }^{7}$. Until recently few studies have investigated the health effects of football training, small sided game (SSG) play and match play ${ }^{8}$.These investigations, typically conducted over 12 weeks with two-three 60 min sessions per week, have shown positive health benefits linked to football participation such as muscular hypertrophy and increases in strength ${ }^{9}$, 
a decrease in blood pressure ${ }^{10}$, decreases in total fat mass ${ }^{11}$ as well as increases in $\dot{V} 0_{2 \max }{ }^{12}$. Therefore there may be a potential for football to remove the social barriers commonly perceived by the HTR population, and allow these interventions to provide the many health benefits observed within the literature.

Research into the health effects of recreational football ${ }^{13}$ to date has typically employed well controlled experimental designs that predominately utilise carefully prescribed football-related activities. Furthermore, participants within these investigations are typically healthy and untrained who volunteer for the research. Such programmes are also typified by high levels of compliance to study requirements and regular attendance at sessions throughout the training programme. Golay et al. (2013) suggested ${ }^{14}$ that 'real life' participation in such programmes or trials do not necessarily reflect study cohorts and can be influenced from factors outside the realm of the programme or trial. The framework employed within much of the previous literature may therefore not reflect the reality of provision within a typical community-based programme that uses skills coaches to deliver football sessions as a vehicle for health promotion. Such programmes,where the structure of training activities and the level of participant commitment may be more varied, may have the potential to reduce the effectiveness of footballbased interventions. These concerns could be further amplified by participants from HTR populationswho decline formal treatment, lack motivation and lead unconventional lifestyles.

The present study aimed to evaluate the effectiveness of regular participation in recreational football, as part of a Football in the Community (FitC) health programme, on markers of health within a hard-to-reach population. 


\section{Materials and Methods}

\section{Experimental Design}

All participantswere involved in a 12-week football-coached intervention programme. Two football sessions lasting 120 minutes in duration were completed each week as the exercise stimulus, with heart rate(HR) continually monitored to measure exercise intensity, following the measurement of $\mathrm{HR}_{\max }$ (described below). To evaluate the health impact of the intervention health related physiological testing was completed at 3 time points during the study (Weeks-1, 6 and 12).This included body composition, blood pressure and cholesterol. Participants were familiarised with the training programme, testing procedures and gave their written informed consent to participate in the study and provide all additional measurements in accordance with the ethical clearance providedby the Universities ethicscommittee prior to the study completion.

\section{Participants}

Nine men (Age: $33 \pm 9$ years, Mass: $75.4 \pm 13.7 \mathrm{~kg}$, Height: $1.74 \pm 0.07 \mathrm{~m}$ and Body Fat: $19 \pm 2 \%$ ) were recruited to participate in the study from a men's homeless shelter and a drug addiction service, who were already in partnership with the FitC health programme at an English Premier League Football Club. Participants were recruited using a variety of mechanisms including face-to-face engagement, phone calls, referrals from service staff and word of mouth.The majority of the participants were smokers, had a history of drug-use (though were recovering and had not taken drugs for at least 6 months) and did not regularly participate in any form of structured physical exercise. Participants were deemed healthy and able to participate following responses given to standardised health questions. These included previous and current medical information around cardio-respiratory, bone and joint health. 
In total, 20 participants signed up to the programme, however, 11 dropped out during the course of the study leaving the final sample to comprise of 9 individuals. Reasons for participant drop out included: depression and mental health issues (causing a lack of engagement), lack of motivation to attend sessions, and trouble with local authorities. The average percentage of attendance of participants to training sessions throughout the programme was $84 \pm 7 \%$. Reasons for non-attendance during the programme included: illness, injury, family issues and situational issues, such as lack of money to travel to the training venue and obligatory appointments with social workers.

\section{Training Intervention}

Outdoor training was completed 2 times per week for 12 weeks on a $20 \mathrm{~m}$ by $30 \mathrm{~m}$ artificial pitch. Each training session was scheduled for 120 minutes. Football sessions were conducted by a qualified FitC coach and generally followed a similar format. Typically this involved a standardised 10-min warm-up comprised of gentle jogging, dynamic, football-related movements (e.g. side-steps, skipping, jumping and lunges), sprinting and dynamic and static stretching. Twenty to thirty min of technical practice (defined as: Individual or group practice covering technical elements under no pressure) was performed, followed by $\sim 20-30 \mathrm{~min}$ of skills practice (defined as: Individual or group practice covering technical elements under opposed pressure), or possession games (defined as: Practice in which ball retention, rather than scoring a goal is the primary objective $)^{15}$. The sessions were concluded with $\sim 30-40$ min of SSG (6v6, 5v5 or 4v4). Sessions differed from this format in weeks 1, 6 and 12 when physical fitness testing was completed during the first session of the week.

HR telemetry was continuously monitored throughout football sessions and was recorded every 5 seconds using HR monitors (Polar Team System, Polar, Kempele, Finland). The mean HR of each individual training activity (i.e. warm up, technical practice, skills/possession practice and 
SSG) was determined and used for analysis. The mean HR collected throughout the entire session provided an indication of the overall session intensity. Participant's maximal HR $\left(\mathrm{HR}_{\max }\right)$ was determined from the HR peak recorded during the Yo-Yo Intermittent Endurance Level 1(Yo-Yo IE1) test. This enabled the collected HR data to also be expressed as a percentage of the individuals $\mathrm{HR}_{\max }$. Rating of perceived exertion (RPE) was collected at the end of each sessionand determined using Borg's CR10-scale ${ }^{16}$. Training load (RPEload) was determined by multiplying the training duration (minutes) by the session RPE, as previously described $^{17}$. This RPE-based method of training load quantification has been shown to be a good indicator of internal training load in football ${ }^{18}$.

\section{Testing Procedures and Measurements}

Testing was completed 3 times during the study (Weeks 1, 6 and 12), with participant's attending the laboratory for health screening. All testing procedures were explained and demonstrated to participants prior to the completion of the assessment. Participant's body composition was assessed via Dual-energy X-ray Absorptiometry (DXA) (Hologic QDR Series Discovery A, Bedfored, MA). Height and mass measurements were taken according to the anthropometric profile recommended by the International Society for the advancement of Kinantropometry (ISAK) ${ }^{19}$ using a Stadiometer (Seca, Germany) and electronic weighing scales (Seca, Hamburg, Germany). Blood pressure and resting heart rate were measured using an automatic upper arm blood pressure monitor (Dynamap, Critikon, UK) following a 5 min period of seated rest. Two measurements were recorded and an average calculated from this data for the final recorded measurement. Blood samples were obtained from the antecubital vein in $2 \mathrm{~mL}$ syringes without heparin. Plasma from centrifuged samples was collected and stored at $-20^{\circ} \mathrm{C}$ until subsequent analysis. High density lipoprotein (HDL), low density lipoprotein (LDL), triglycerides and total cholesterol were determined flourometrically on an 
automatic analyser (RX Daytona, Randox Laboratory, Antrim, UK).All samples were measured in duplicate following completion of the 12 -week programme using the samecommercially available enzymatic spectrophotometric assays (RX Daytona Analyser, Randox Laboratories, Antrim, UK). Co-efficient of variation for these assay kits were $1.47 \%, 1.80 \%, 3.29 \%$ and $3.73 \%$ for HDL, LDL, triglycerides and total cholesterol respectively.

\section{Statistics}

Data are presented as means \pm standard deviation (SD). All data were assessed for the assumption of normality using the Shapiro-Wilks test for normality of distribution. Mauchly's test of sphericity was performed on all data to assess for the assumption of sphericity. However, no corrections were required following these assessments. Within-group data for all variables for pre-, mid- and post-testing (Weeks-1, -6, and -12) were evaluated by one-way analysis of variance on repeated measures (ANOVA). The level of statistical significance was set at $\mathrm{P}<$ 0.05. When a significant effectwas detected, data were subsequently analysed using Bonferonni corrected pair-wise comparison post-hoc test. All statistical analyses were carried out using SPSS Statistical Analysis Software (SPSS ${ }^{\circledR}$ Version 15.0.01 for Windows ${ }^{\circledR}$, Chicago, Illinois, USA).

\section{Results}

\section{Physiological response to training}

Average heart rate during sessions across the 12 weeks was $138 \pm 7$ beats. min $^{-1}$. This corresponded to around $75 \pm 4 \% \mathrm{HR}_{\max }$. Average time spent $>90 \% \mathrm{HR}_{\max }$ for each session was $13 \pm 7$ min (Table 1), corresponding to $15 \%$ of training time. Mean RPE for the sessions was $6 \pm 1$ (VAS 1-10). This data gave an RPE load $_{\text {of }} 475 \pm 71$ (Table 1). Average heart rate during the warm-up, technical practice, skills / possession practice and SSG were $67 \pm 6,71 \pm 4,76 \pm 5$ and 
$82 \pm 7 \% \mathrm{HR}_{\max }$ respectively (Figure 1.). Figure 2 provides an individual insight into the sessional HR response for a typical training session.

\section{Blood Pressure and Resting Heart Rate}

No differences $(\mathrm{P}=1.00)$ were observed for RHR between weeks-1 and -6 . Resting heart rate

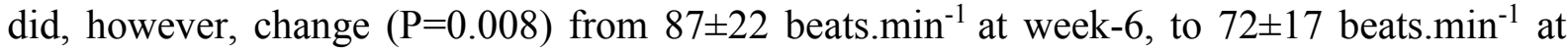
week-12 (Table 2. and Figure 3.). No changes were observed in resting systolic $(p=0.711)$ or diastolic $(\mathrm{p}=0.824)$ blood pressure following 12-weeks of training (Table 2.).

\section{Body Composition and Blood Analysis}

No changes occurred over 12-weeks of training for total mass $(p=0.144)$, fat $(p=0.173)$ and lean mass $(\mathrm{p}=0.484)$, bone mineral density $(B M D)(p=0.199)$ and $\%$ body fat $(p=0.098)$ (Table 2.). Similarly, no changes were observed over 12-weeks of training for blood lipid markers, including HDL $(p=0.187)$, LDL $(p=0.487)$, triglycerides $(p=0.541)$ and total cholesterol $(\mathrm{p}=0.108)$ (Table 3.).

\section{Discussion}

The primary aim of the current investigation was to examine markers of health before and aftera 12-week Football in the Community (FitC) health programme. The main finding was that 12weeks of a recreational community based football training programme elicited little or no changes in physiological markers of health as reflected by HR, blood pressure, body composition and blood lipid profile. However, it could be suggested that the programme was successful in maintaininghealth, as the participants baseline data suggests that they were not especially unhealthy. The failure to find positive changes in health may be consequence of the myriad of problems associated with the delivery of such programmes within the community 
based setting (e.g. participant attendance). They may also be a result of the relatively low exercise intensity associated with the sessions included in the intervention. This intensity is probably a direct result of the organisation of the activities within the session. This may highlight the need for better coach education training for the delivery of community programmes.

The training programme included in the intervention had limited impact on a selected range of markers of health in our HTR population. No changes were observed in blood pressure, body composition (including; fat mass, lean mass, \%body fat and BMD) and blood lipid profile. The findings in the current investigation are in contrast to previous research that indicated that recreational football training, with an approximate intensity of $80-85 \%$ generated during a 60 120 min session 2-3 times per week, was effective in reducing blood pressure. For example, previous investigations ${ }^{20}$ have observed reductions in systolic and diastolic blood pressure of 8 and $5 \mathrm{mmHg}$ respectively, following 12-weeks of training. Recent studies have also typically observed reductions in total mass, fat mass and \% body fat as well as increases in leg muscle mass and BMD following a period of recreational football training ${ }^{21}$. This data is also in contrast to our findings. Resting HR was the only variable to decrease following 12-weeks of recreational football training (Table 2) in the current investigation. The decrease in resting HR as observed in previous studies ${ }^{22}$ may reflect a reduction in sympathetic outflow and thereby reduced systemic vascular restrictions. Regardless of the lack of physiological change observed, it cannot be ascertained if the programme resulted in other adaptations in either behavioural and/or psychological characteristics. Such changes have previously been seen in other investigations $^{23}$, though were not measured here.

Mean weekly time spent above $90 \% \mathrm{HR}_{\max }$ equated to $13 \pm 7$ mins throughout the 12 training weeks. This may have been thought to be sufficient to induce a positive health increase as previous studies ${ }^{24}$ demonstrate, although still lower than Randers et al. (2012) who found their 
street soccer programme resulted in $21 \pm 12$ mins above $90 \% \mathrm{HR}_{\max }$. The lack of significance amongst the physiological variablescould partially be attributed to the depletion of the statistical power due to the withdrawal of 11 participants from the original group of 20. This may have decreased the likelihood of any statistical difference from several of the variables measured, as positive improvements are clear but not to significance. This, and the lack of a control group, is a clear limitation of this investigation. Another possible explanation for the lack of health benefits observed following the programme may be linked to the overall exercise intensity achieved during the sessions. The overall average intensity of the football sessions conducted throughout the 12 -week programme was $75 \pm 4 \% \mathrm{HR}_{\max }$. This is considerably lower than reported in recent research that hasutilised a more controlled exercise prescription such as $\mathrm{SSG}^{25}$. The main disparity in the overall exercise intensity within our investigation seemed to have occurred as a consequence of the structure of the session, more specifically the inclusion of football drills and technical practices. Average heart rates during technical practice and skills / possession practice were $71 \pm 4$ and $76 \pm 5 \% \mathrm{HR}_{\max }$ respectively (Figure 1.). This is lower than the $82 \% \mathrm{HR}_{\max }$ associated with the SSG's completed at the end of the session. The intensity of exercise is thought to act as a key primer for any physiological adaptations associated with chronic training programmes ${ }^{26}$.The previous research discussed ${ }^{27}$ would suggest that an overall intensity between $80-85 \% \mathrm{HR}_{\max }$ would induce adaptation within a healthy population, similar to those described in the current investigation. Therefore, it appears that the inclusion of technically orientated football drills may have lowered the overall exercise intensity of the session and limited the time that each participant was required to work at near maximal levels of cardiovascular stress. This may suggest that programmes that do not create high physiological loads may not be effective in eliciting positive health gains. Thus, the absence of change in physiological markers of health observed in the current study could be explained by an insufficient training stimulus. An additional factor that may have explain the lack of 
effectiveness ofthe programme was the reduced average duration of the sessions $(88 \pm 18 \mathrm{~min}$, see Table 1) when compared to scheduledcompletion time of 120 mins. This discrepancy was accredited to poor timekeeping of the HTR population, which severely restricted the ability of the coach to run the session for the appropriate duration.

Exercise conducted as part of community-based football health programmes may therefore, need to be more highly controlled from a physiological viewpoint in order to elicit the desired adaptations that may lead to improvements in health status. Beneficial adaptations to the exercise incorporated in such programmes could include a greater reliance on SSG's or a manipulation of any technically orientated football drill included within the session to increase the physiological load. For example, the size of area, number of players, and the exercise to rest ratio are all important determinants of the overall physiological stress associated with the training stimulus ${ }^{28}$ that could be manipulated by the coach to improve the fitness outcomes of the session. Furthermore, SSGs have resulted in lower RPE values than jogging, interval training and strength training ${ }^{29}$. Providing more evidence for the use of SSGs. The current investigation found a higher RPE responses compared to the study by Elbe et al. (2010), although this may be due to the inclusions of training drills, and may have affected participant retention.There is also a need for further research to investigate the optimal dose response for beneficial health adaptations. It could be speculated that training twice per week for $60-120$ mins would be suffice, although this may be dependent on the baseline health of the population undertaking the programme. There is a lack of understanding as to the effect of shorter football training or SSG sessions conducted and maintaining higher exercise intensities. This may be appropriate for populations that are not unhealthy, such as a more aggressive and intense programme can be prescribed, although more research is needed to investigate this hypothesis. Another potential aspect to consideris the development of appropriate standards of coach education for practitioners involved in this type of programme. Typically the coaches that lead 
community based programmes complete the same educational programmes as coaches who focus on the development of players from a technical and tactical perspective. This type of syllabus may not be suitable for the delivery of a knowledge base that equips individuals to deliver football sessions that are aimed at providing a suitable physiological intensity to improve markers of health. This study illustrates that the intensity of the session is paramount in providing beneficial health gains for participants, which may require the use of appropriate measures forthe monitoring of the intensity to ensure that the coaches are providing a sufficient load to generate the physiologic and metabolic adaptations. However, the coaches may also need to be mindful of the psychological issues that may impact the participation and potential behavioural change. It is important that the training does not simply become fitness based drills to increase intensity, but retain the inclusion of football based drills and SSGs carefully designed to generate sufficient intensity, as these have shown to provide increases in motivation that can increase physical activity compliance.

In conclusion, community-based football projects endorsed by elite teams may be successful at engaging those from HTR populations and important to combat increasing levels of physical inactivity in the general population and associated levels of obesity and cardiovascular diseases. However, the current study suggests that exercise administered during these programmes may not be efficient in promoting positive health changes, although it was successful in maintaining health over the 12-week intervention. As the HTR population were not necessarily unhealthy, more time could be prescribed for SSGs that may not only increase intensity, but also lower RPE, yet maintain participation. It is important for long-term success that the education of participants and healthy lifestyle messages endorsed by such programmes are supported by measurable positive health adaptations. As such, careful consideration needs to be taken when planning training programmes. The completion of a suitable amount of exercise at a high 
intensity would seem to be an important component of such a planning process. This may necessitate the improved training and education programmes of personal that are required to deliver the programmes.

\section{Acknowledgements}

The authors would like to express their gratitude to the participants of the Premier League Health programme and the staff of Everton in the Community and Everton Football Club.

\section{Notes:}

\footnotetext{
${ }^{1}$ Pringle et al., 'Effect of a national programme of men's health delivered in English Premier League football clubs'.

${ }^{2}$ World Health Organization, 'Social determinants of health'.

${ }^{3}$ Faugier and Sargeant, 'Sampling hard to reach populations.

${ }^{4}$ Witty and White, 'The Tackling Men's Health evaluation study'

${ }^{5}$ Randers et al., 'Positive performance and health effects of a football training program over 12 -weeks can be maintained over a 1-year period with reduced training frequency'; Krustrup et al., 'Recreational soccer is an effective health promoting activity for untrained men'.

${ }^{6}$ Wilkins and Baker, 'Getting it Sorted: a policy programme for men's health'.

${ }^{7}$ Gough, 'The psychology of men's health: Maximising masculine capital'.

${ }^{8}$ Krustrup et al., 'Effects on training status and health profile of prolonged participation in recreational football: heart rate response to recreational training and match-play'; Krustrup et al., 'Recreational soccer is an effective health promoting activity for untrained men'; Bangsbo et al., 'Performance enhancements and muscular adaptations of a 16-week recreational football intervention for untrained women'; Anderson et al., 'Football as a treatment for hypertension in untrained 30-55 year-old men: a prospective randomized study'; Randers et al., 'Positive performance and health effects of a football training program over 12 -weeks can be maintained over a 1 -year period with reduced training frequency'.

${ }^{9}$ Krustrup et al., 'Recreational soccer is an effective health promoting activity for untrained men'

${ }^{10}$ Anderson et al., 'Football as a treatment for hypertension in untrained 30-55 year-old men: a prospective randomized study'.

${ }^{11}$ Randers et al., 'Positive performance and health effects of a football training program over 12 -weeks can be maintained over a 1-year period with reduced training frequency'.

${ }^{12}$ Krustrup et al., 'Muscle adaptations and performance enhancements of soccer training for untrained men'.

${ }^{13}$ Krustrup et al., 'Effects on training status and health profile of prolonged participation in recreational football: heart rate response to recreational training and match-play'; Krustrup et al., 'Recreational soccer is an effective health promoting activity for untrained men'; Bangsbo et al., 'Performance enhancements and muscular adaptations of a 16-week recreational football intervention for untrained women'; Anderson et al., 'Football as a treatment for hypertension in untrained 30-55 year-old men: a prospective randomized study'; Randers et al., 'Positive performance and health effects of a football training program over 12 -weeks can be maintained over a 1 -year period with reduced training frequency'.

${ }^{14}$ Golay et al., 'Taking small steps towards targets - perspectives for clinical practice in diabetes, cardiometabolic disorders and beyond'.
} 
${ }^{15}$ Yates and Williams, 'The microstructure of practice in soccer: A comparison of duration and frequency of practice'

${ }^{16}$ Foster et al., Effects of specific versus cross-training on running performance'.

${ }^{17}$ Foster et al., Effects of specific versus cross-training on running performance'.

${ }^{18}$ Imellizzeri et al., 'Use of RPE-based training load in soccer'.

${ }^{19}$ Marfell-Jones et al., International standards for anthropometrical assessment'.

${ }^{20}$ Krustrup et al., 'Recreational soccer is an effective health promoting activity for untrained men'.

${ }^{21}$ Bangsbo et al., 'Performance enhancements and muscular adaptations of a 16-week recreational football intervention for untrained women'; Krustrup et al., 'Recreational soccer is an effective health promoting activity for untrained men'; Krustrup et al., 'Muscle adaptations and performance enhancements of soccer training for untrained men'; Randers et al., 'Positive performance and health effects of a football training program over 12weeks can be maintained over a 1 -year period with reduced training frequency'.

${ }^{22}$ Krustrup et al., 'Recreational soccer is an effective health promoting activity for untrained men'; Anderson et al., 'Football as a treatment for hypertension in untrained 30-55 year-old men: a prospective randomized study'; Randers et al., 'Positive performance and health effects of a football training program over 12 -weeks can be maintained over a 1-year period with reduced training frequency'.

${ }^{23}$ Pringle et al., Effect of a national programme of men's health delivered in English Premier League football clubs'.

${ }^{24}$ Nybo et al., 'High-intensity training versus traditional exercise interventions for promoting health'; Krustrup et al., 'Recreational soccer is an effective health promoting activity for untrained men',

${ }^{25}$ Bangsbo et al., 'Performance enhancements and muscular adaptations of a 16 -week recreational football intervention for untrained women'; Krustrup et al., 'Recreational soccer is an effective health promoting activity for untrained men'; Krustrup et al., 'Muscle adaptations and performance enhancements of soccer training for untrained men'; Randers et al., 'Positive performance and health effects of a football training program over 12weeks can be maintained over a 1 -year period with reduced training frequency'.

${ }^{26}$ Nybo et al., 'High-intensity training versus traditional exercise interventions for promoting health'.

${ }^{27}$ Bangsbo et al., 'Performance enhancements and muscular adaptations of a 16 -week recreational football intervention for untrained women'; Krustrup et al., 'Recreational soccer is an effective health promoting activity for untrained men'; Krustrup et al., 'Muscle adaptations and performance enhancements of soccer training for untrained men'; Randers et al., 'Positive performance and health effects of a football training program over 12weeks can be maintained over a 1-year period with reduced training frequency'.

${ }^{28}$ Köklüet et al., Comparison of the physiological responses to different small-sided games in elite young soccer players'.

${ }^{29}$ Elbe et al., Experiencing flow in different types of physical activity intervention programs: three randomized studies'.

\section{References}

Andersen, L.J., M.B. Randers, K. Westh, D. Martone, P.R. Hansen, A. Junge, J. Dvorak, J. Bangsbo and P. Krustrup. 'Football as a treatment for hypertension in untrained 30-55 year-old men: a prospective randomized study'. Scandinavian Journal of Medicine \& Science in Sports, 20 (2010): 98-102.

Bangsbo, J., J.J. Nielsen, M. Mohr, M.B. Randers, B.R. Krustrup, J. Brito, L. Nybo and P. Krustrup. 'Performance enhancements and muscular adaptations of a 16-week recreational football intervention for untrained women'. Scandinavian Journal of Medicine \& Science in Sports, 20 (2010): 24-30.

Bergeron, M.F. 'Improving health through youth sports: Is participation enough?' New Directions in Youth Development, 115 (2007): 27-41.

Elbe, A.M., K. Strahler, P. Krustrup, J. Wikman and R. Stelter. 'Experiencing flow in different types of physical activity intervention programs: three randomized studies'. Scandinavian Journal of Medicine \& Science in Sports, 20 Supplement (2010): 111-7. 
Foster, C., L. Hector, R. Welsh, M. Schrager, M.A. Green, and A.C. Snyder. 'Effects of specific versus cross-training on running performance'. European Journal of Applied Physiology and Occupational Physiology, 70 (1995): 367-372.

Faugier, J. and M. Sargeant. 'Sampling hard to reach populations'. Journal of Advanced Nursing, 26 (1997):790-7.

Golay, A., E. Brock, R. Gabriel, T. Konrad, N. Lalic, M. Laville, G. Mingrone, J. Petrie, T.M. Phan, K.H. Pietiläinen and C.H. Anderwald. 'Taking small steps towards targets - perspectives for clinical practice in diabetes, cardiometabolic disorders and beyond'. International Journal of Clinical Practice, 67 (2013): 322-32.

Gough, B. 'The psychology of men's health: Maximising masculine capital'. Health Psychology, 32 (2013): 32: 1-4.

Helgerud, J., L.C. Engen, V. Wisloff and J. Hoff. 'Aerobic endurance training improves soccer performance'. Medicine and Science in Sports and Exercise, 33 (2001): 1925 - 1931.

Impellizzeri, F.M., E. Rampinini, A.J. Coutts, A. Sassi and S.M. Marcora. 'Use of RPEbased training load in soccer'. Medicine and Science in Sports and Exercise, 36 (2004):10427.

Köklü, Y., A. Aşçi, F.U. Koçak, U. Alemdaroğlu and U. Dündar. 'Comparison of the physiological responses to different small-sided games in elite young soccer players'. Journal of Strength and Conditioning Research, 25 (2011): 1522-1528.

Krustrup, P. and J. Bangsbo. 'Physiological demands of top-class soccer refereeing in relation to physical capacity: effect of intense intermittent exercise training'. Journal of Sports Science, 19 (2001): 811-891.

Krustrup, B.R., I. Rollo, J.N. Nielsen and P. Krustrup. 'Effects on training status and health profile of prolonged participation in recreational football: heart rate response to recreational training and match-play'. Journal of Sports Science and Medicine, 6 (2007): 116-117.

Krustrup, P., J.J. Nielsen, B. Krustrup, J.F. Christensen, H. Pedersen, M.B. Randers, P. Aagaard, A.M. Petersen, L. Nybo and J. Bangsbo. 'Recreational soccer is an effective health promoting activity for untrained men'. British Journal of Sports Medicine, 43 (2009): 825-831.

Krustrup, P., J.F. Christensen, M.B. Randers, H. Pedersen, E. Sundstrup, M.D. Jakobsen, B.R. Krustrup, J.J. Nielsen, C. Suetta, L. Nybo and J. Bangsbo. 'Muscle adaptations and performance enhancements of soccer training for untrained men'. European Journal of Applied Physiology, 108 (2010a): 1247-1258.

Krustrup, P., P.R. Hansen, M.B. Randers, L. Nybo, D. Martone, L.J. Andersen, L.T. Bune, A. Junge and J. Bangsbo. 'Beneficial effects of recreational football on the cardiovascular risk profile in untrained premenopausal women'. Scandinavian Journal of Medicine \& Science in Sports, 20 (2010b): 40-49.

Lee, I.M. and P.J. Skerrett. 'Physical activity and all-cause mortality: what is the dose-response relation?' Medicine and Science in Sports and Exercise, 34 (2001): 592-595.

Marfell-Jones, M., T. Olds, A. Stewart and J.E.L. Carter. 'International standards for anthropometrical assessment'. Potchesfstroom: International Society for the Advancement of Kinanthtopometry, (2006): 1-137. 
Nybo, L., E. Sundstrup, M.D. Jakobsen, M. Mohr, T. Hornstrup, L. Simonsen, J. Bülow, M.B. Randers, J.J. Nielsen, P. Aagaar and P. Krustrup. 'High-intensity training versus traditional exercise interventions for promoting health'. Medicine and Science in Sports and Exercise, 42 (2010): 1951-1958.

Pringle, A., S. Zwolinsky, A. Smith, S. Robertson, J. McKenna and A. White. 'The pre-adoption demographic and heath profiles of men participating in a programme of men's health delivered in English Premier League football clubs'. Public Health, 125 (2011): 411-416.

Pringle, A., S. Zwolinsky, J. McKenna, A. Daly-Smith, S. Robertson and A. White. 'Effect of a national programme of men's health delivered in English Premier League football clubs'. Public Health 176 (2013): 18-26.

Randers, M.B., J.J. Nielsen, B.R. Krustrup, E. Sundstrup, M.D. Jakobsen, L. Nybo, J. Dvorak, J. Bangsbo and P. Krustrup. 'Positive performance and health effects of a football training program over 12-weeks can be maintained over a 1-year period with reduced training frequency'. Scandinavian Journal of Medicine \& Science in Sports, 20 (2010): 80-89.

Randers, M.P., J. Petersen, L.J. Andersen, B.R. Krustrup, T. Hornstrup, J.J. Nielsen, M. Nordentoft and P. Krustrup. 'Short-term street soccer improves fitness and cardiovascular health status of homeless men'. European Journal of Applied Physiology, 112 (2012): 20972106.

World Health Organisation. (2003). Social Determinants of Health. Available at: http://www.who.int/social_determinants/publications/en/ [Accessed July 2013]

Wilkins, D. and P. Baker. (2003). Getting it Sorted: a policy programme for men's health. London: Men's Health Forum.

Witty, K. and A. White. (2010). The Tackling Men's Health evaluation study. Leeds: Centre for Men's Health, Leeds Metropolitan University.

Yates, I.S. and A.M. Williams. (2008). 'The microstructure of practice in soccer: A comparison of duration and frequency of practice'. In T. Reilly, \& F. Korkusuz (Eds.), Science and Football VI, Proceedings of the $6^{\text {th }}$ World Congress in Science and Football (pp. 437-441). Antalya, Turkey.

\section{Tables and Figures}


Table 1.Mean \pm SD data $(n=9)$ for session duration, RPE, RPE Load,and HR training data for 12 weeks of football training. Mean HR data is the mean of both sessions during the week.

\begin{tabular}{|c|c|c|c|c|c|c|}
\hline Week & $\begin{array}{l}\text { Mean } \\
\text { Session } \\
\text { Duration } \\
\text { (min) }\end{array}$ & $\begin{array}{l}\text { RPE } \\
\text { (VAS1-10) }\end{array}$ & RPE load & $\begin{array}{l}\text { Overall } \\
\text { Mean } \\
\text { Heart Rate } \\
\text { (beats.min } \\
{ }^{1} \text { ) } \\
\end{array}$ & $\% H R_{\max }$ & $\begin{array}{l}\text { Time }>90 \% \\
\mathbf{H R}_{\max } \\
(\min )\end{array}$ \\
\hline Week 1 & $73 \pm 30$ & $7 \pm 0$ & 511 & $136 \pm 24$ & $75 \pm 3$ & $10 \pm 6$ \\
\hline Week 2 & $74 \pm 35$ & $6 \pm 1$ & 444 & $135 \pm 16$ & $74 \pm 3$ & $2 \pm 2$ \\
\hline Week 3 & $104 \pm 7$ & $5 \pm 1$ & 521 & $145 \pm 20$ & $79 \pm 3$ & $21 \pm 18$ \\
\hline Week 4 & $93 \pm 0$ & $6 \pm 0$ & 558 & $132 \pm 18$ & $72 \pm 3$ & $10 \pm 15$ \\
\hline Week 5 & $89 \pm 1$ & $6 \pm 2$ & 534 & $136 \pm 23$ & $74 \pm 3$ & $15 \pm 15$ \\
\hline Week 6 & $80 \pm 37$ & $5 \pm 1$ & 400 & $133 \pm 24$ & $73 \pm 3$ & $8 \pm 11$ \\
\hline Week 7 & $92 \pm 4$ & $6 \pm 2$ & 552 & $148 \pm 22$ & $81 \pm 3$ & $21 \pm 18$ \\
\hline Week 8 & $99 \pm 2$ & $4 \pm 0$ & 396 & $141 \pm 21$ & $77 \pm 3$ & $17 \pm 15$ \\
\hline Week 9 & $92 \pm 11$ & $5 \pm 1$ & 460 & $132 \pm 19$ & $72 \pm 3$ & $14 \pm 12$ \\
\hline Week 10 & $100 \pm 0$ & $4 \pm 0$ & 400 & $140 \pm 25$ & $76 \pm 3$ & $14 \pm 15$ \\
\hline Week 11 & $92 \pm 3$ & $6 \pm 1$ & 552 & $143 \pm 19$ & $78 \pm 3$ & $12 \pm 15$ \\
\hline Week 12 & $53 \pm 0$ & $7 \pm 0$ & 371 & $132 \pm 24$ & $72 \pm 3$ & $7 \pm 7$ \\
\hline $\begin{array}{l}\text { Overall } \\
\text { Mean } \pm \\
\text { SD }\end{array}$ & $88 \pm 18$ & $6 \pm 1$ & $475 \pm 71$ & $138 \pm 7$ & $75 \pm 3$ & $13 \pm 7$ \\
\hline
\end{tabular}


Table 2.Mean \pm SD Group body composition, blood pressure and resting heart rate for Weeks 1,6 and 12 .

\begin{tabular}{|c|c|c|c|}
\hline & Week 1 & Week 6 & Week 12 \\
\hline \multicolumn{4}{|l|}{ Body Composition } \\
\hline Mass $(\mathrm{kg})$ & $75.4 \pm 13.7$ & $74.7 \pm 13.7$ & $74.0 \pm 14.7$ \\
\hline BMI & 24.85 & 24.62 & 24.39 \\
\hline $\operatorname{BMD}\left(\mathrm{g} \cdot \mathrm{cm}^{2}\right)$ & $1.240 \pm 0.135$ & $1.247 \pm 0.124$ & $\begin{array}{l}1.194 \pm \\
0.093\end{array}$ \\
\hline Fat Mass $(\mathrm{kg})^{*}$ & $13.9 \pm 6.4$ & $14.7 \pm 7.3$ & $13.8 \pm 6.3$ \\
\hline Lean Mass $(\mathrm{kg})^{*}$ & $54.0 \pm 8.9$ & $53.6 \pm 8.3$ & $55.0 \pm 9.7$ \\
\hline Total Fat $(\%)^{*}$ & $19.2 \pm 5.8$ & $20.2 \pm 6.4$ & $18.9 \pm 5.6$ \\
\hline \multicolumn{4}{|l|}{ Blood Pressure } \\
\hline Systolic BP (mmHg) & $134 \pm 14$ & $134 \pm 12$ & $131 \pm 11$ \\
\hline Diastolic BP $(\mathrm{mmHg})$ & $76 \pm 13$ & $78 \pm 9$ & $79 \pm 9$ \\
\hline RHR (beats. $\min ^{-1}$ ) & $88 \pm 20$ & $87 \pm 22$ & $72 \pm 17^{\# * *}$ \\
\hline $\begin{array}{l}\text { BMD - Bone mineral c } \\
\text { Pressure, RHR - Restir } \\
\text { * Indicates subtotal val } \\
\text { \# Significant difference } \\
\text { **Indicates significant }\end{array}$ & $\begin{array}{l}\text { - Body Mass In } \\
\text { ding head) } \\
1 \\
\text { om Week } 6\end{array}$ & P - Blood & \\
\hline
\end{tabular}

Table 3.Mean \pm SD blood lipid values for Weeks 1, 6 and 12. 


\begin{tabular}{lccc}
\hline & Week 1 & Week 6 & Week 12 \\
\hline Cholesterol (mmol/L) & $5.28 \pm 0.83$ & $5.28 \pm 0.49$ & $5.31 \pm 0.79$ \\
Triglycerides (mmol/L) & $1.85 \pm 0.42$ & $2.04 \pm 0.43$ & $1.83 \pm 0.40$ \\
HDL (mmol/L) & $1.10 \pm 0.15$ & $1.13 \pm 0.22$ & $1.12 \pm 0.20$ \\
LDL (mmol/L) & $3.53 \pm 0.95$ & $3.50 \pm 0.81$ & $3.46 \pm 0.92$ \\
HDL/LDL Ratio & $0.85 \pm 0.41$ & $0.95 \pm 0.57$ & $0.79 \pm 0.36$ \\
\hline
\end{tabular}




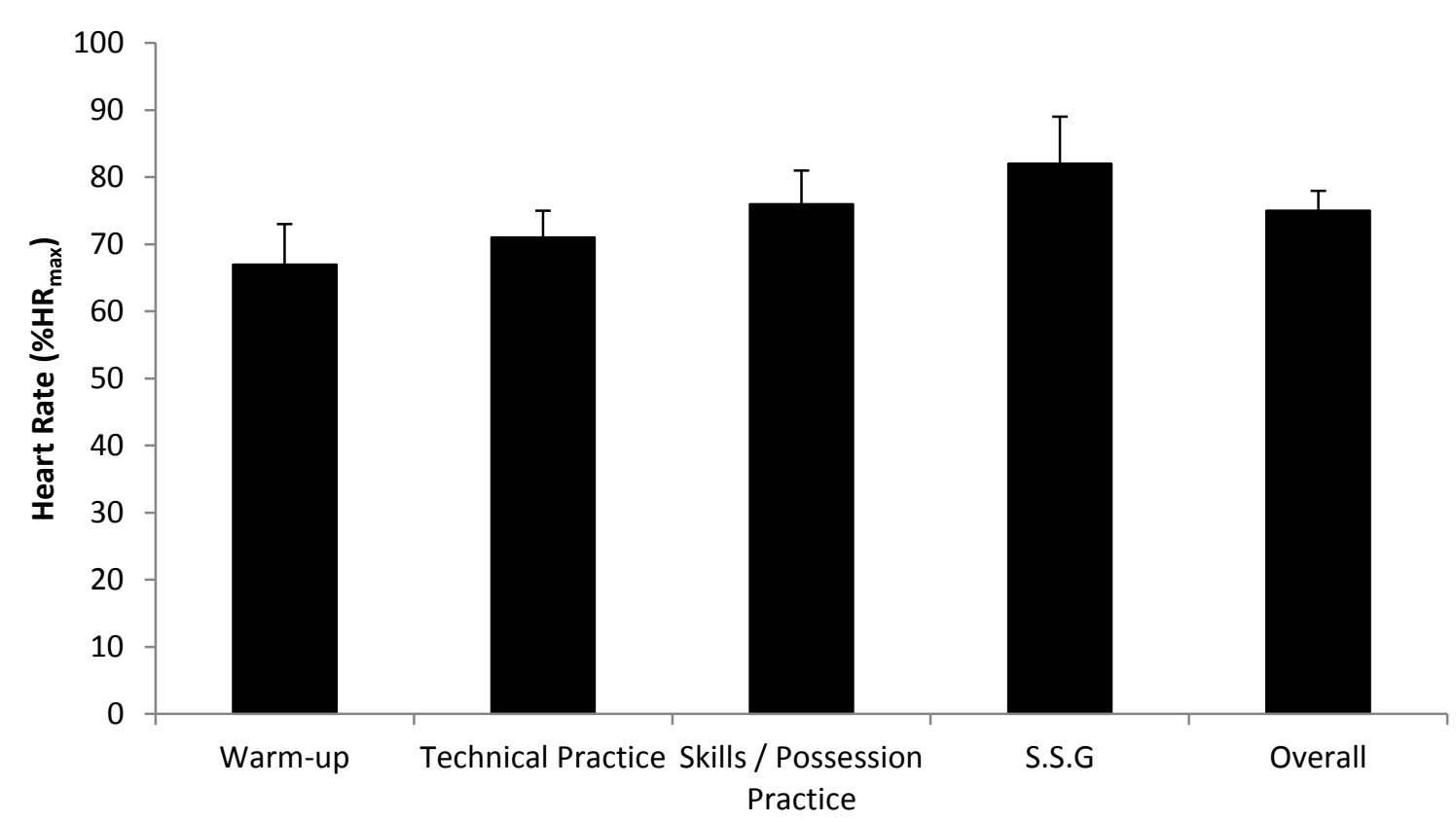

Figure 1.Mean $\pm \mathrm{SD}$ Heart rate values $(\% \mathrm{HR} \max )$ for activity breakdown during football sessions 


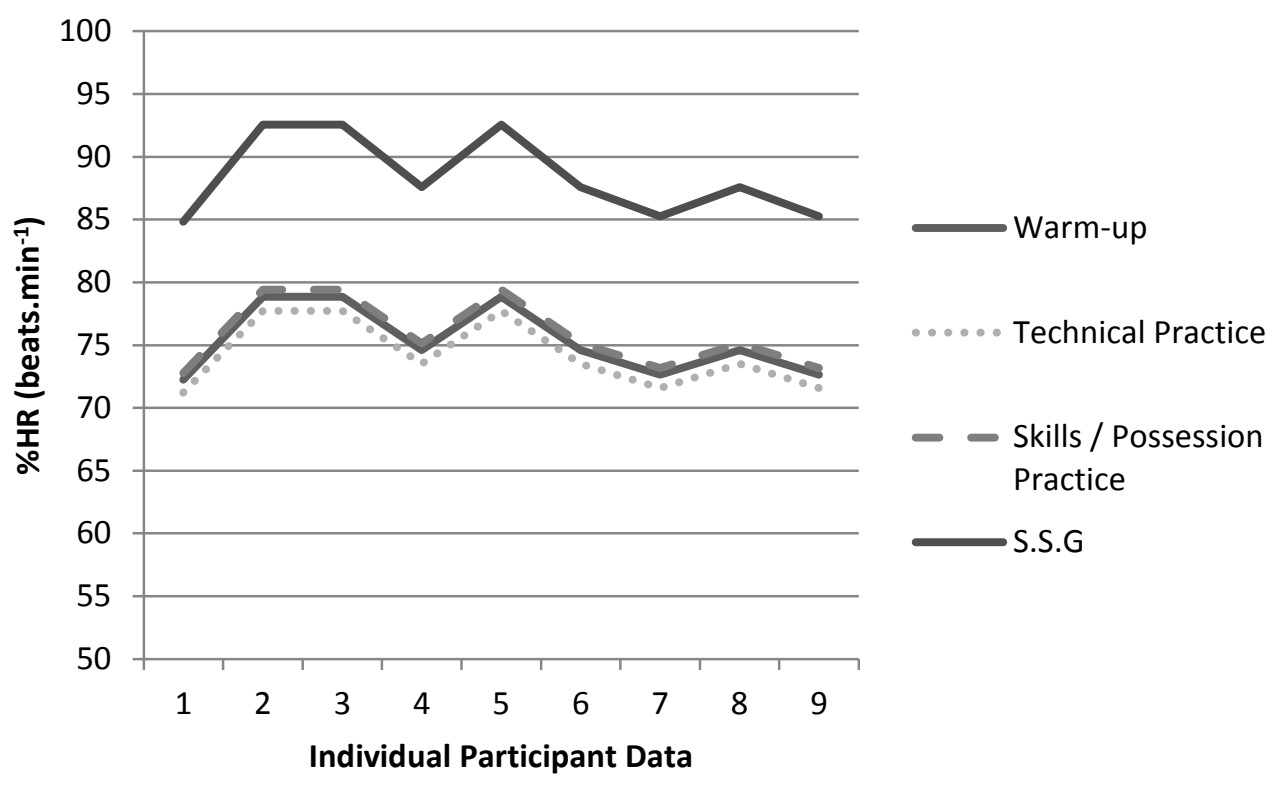

Figure 2.Individual HR data for a single session within the programme, highlighting the variability between participants and HR increase during the SSG. 


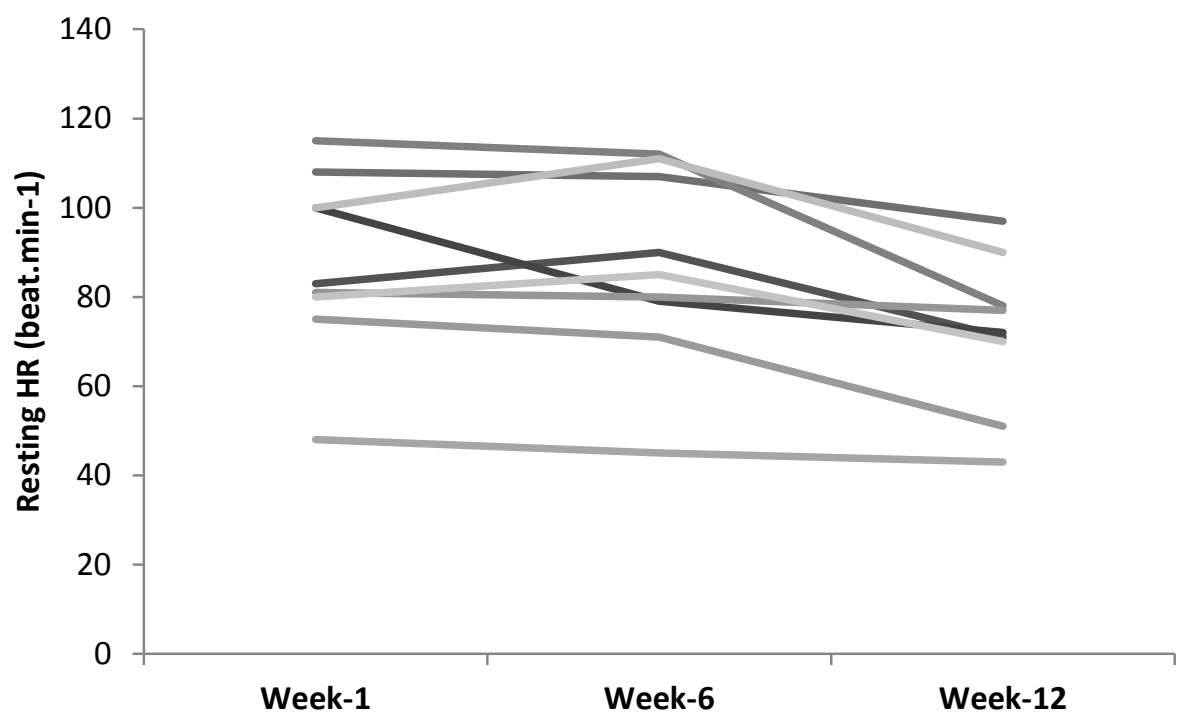

Figure 3. Individual RHR pre, during and post the 12-week training programme. 